
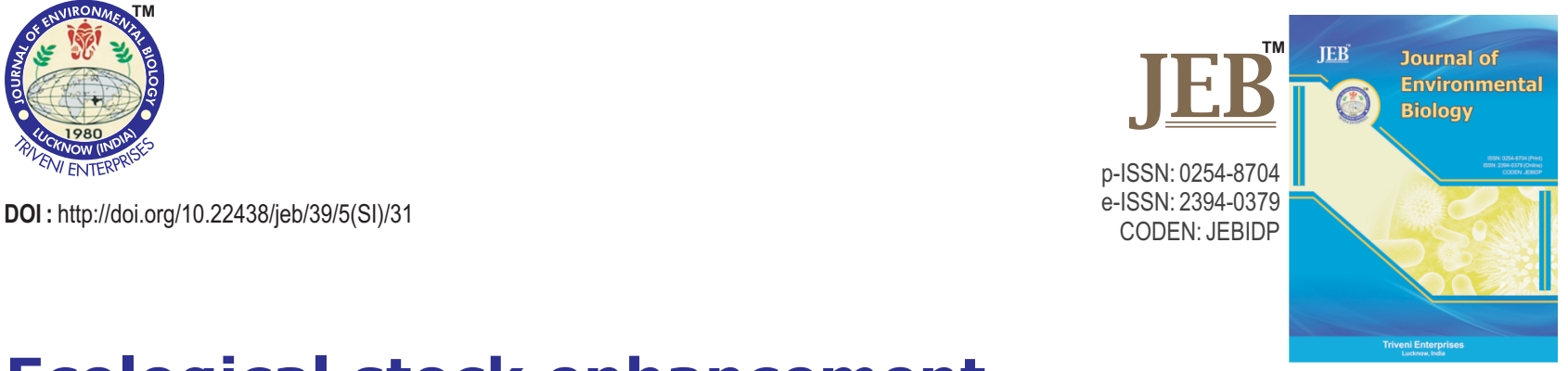

\title{
Ecological stock enhancement programs (ESEPs) based fisheries rebuilding plan (FRP) in Korea
}

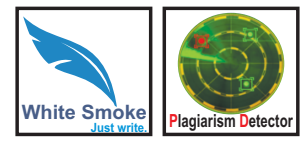

\section{Authors Info \\ Sang-Go Lee ${ }^{1 *}$ and M. Aminur Rahman $^{1,2 *}$ \\ ${ }^{1}$ World Fisheries University Pilot Programme, Pukyong National University (PKNU), 45 Yongso-ro, Nam-gu, Busan-48513, Korea \\ ${ }^{2}$ Laboratory of Marine Biotechnology, Institute of Bioscience, Universiti Putra Malaysia-43400 UPM Serdang, Selangor, Malaysia \\ *Corresponding Author Email sglee@pknu.ac.kr}

Key words

ESE programs

Fish stock

Fisheries rebuilding plan

Socio-bioeconomic outcome

Publication Info

Paper received : 20.02.2017

Revised received : 15.05 .2017

Re-revised received : 25.07 .2017

Accepted : 28.12.2017

\begin{abstract}
Despite various management measures, the coastal and offshore fisheries of Korea have been experienced considerable decrease in fish catch and stock in the early 2000 and therefore, and therefore, the government of Korea sincerely acknowledge the obligation to increase the productivity of fisheries through the retrieval of depleted fish stocks. On the basis of this consideration in mind, the effective fisheries rebuilding plan (FRP), combined with ecological fish stock enhancement programs (ESEPs), was established in the year 2005. The ESEPs-based FRP management strategy conveys remarkable significance. Without the fisheries closures in FRP, ESEPs-based FRP is one of the effective measures to advocate for the most direct and quickest approach to recover catch levels of overfished fish. The ESEPsbased FRP has been operated from 2006 and is expanded to 16 species in 2016 and has changed the focus of fish stock and catch recovery by allowing relevant fisherman to become involved actively in the events of founding and endorsing the programs, accelerating to the efficient execution of the ESEPs. The contemporary ESEPs is being operating by species stocking, has expanded to encompass the whole ecosystem and greatly contributed to more effective way of FRP for all overfished species in coastal and offshore fisheries in Korea. The findings from the ESEPs-based FRP show that fish stocks and recovery of catches are increasing after the implementation of the program. These increasing trends of recovery as well as expansion in the catch of each species unswervingly has specified as a sake of the accomplishment the FRP and it has also resulted from implementing of the ESEPs under the FRP.
\end{abstract}

\section{Introduction}

Korea has overexploited its major fish stocks in a short period, and stock assessment conducted in coastal and offshore fisheries revealed that the total production of fish species decreased consistently from around 10 million tons in 1980 to 7.9 million tons in 2004 (MOF, 2015). Despite efforts of various traditional fisheries management approaches, fish stocks have failed to recover to their sustainable levels.

Korea had conventionally managed the fish stock by implementing technical measures, for instance, closed time, enclosed area, gear types, mesh regulation, as well as control of inputs based on licensing methods of fishing operations by boats and vessels. Along with the technical regulations and harvesting controls, the buyback programs of vessel have been executed since 1994 , and the output control has been utilized by adopting TAC (total allowable catch) policy since 1999 (NFDRI, 2004). In addition to these traditional management measures, ESEPs such as marine ranching program, fish fry releasing program, artificial reef and seaweed forest establishment programs have also been initiated to enhance the fish stocks for offshore and coastal fisheries. 
The ESEPs-based fisheries rebuilding plan (FRP) is the most recent effort devised to improve the situation of the stocks declining fish. It has been established and implemented since 2006 aims to recover and rebuild deteriorating stocks biomass towards a target level in a specific period through the ESEPs to subsequently improve catch of target species. A recent study (MOF, 2015) reported that catches of target species have improved from pilot projects initially carried out; however, it is not definite that this increase is impacted by FRP. According Lee and Midani (2014), 2015 marks the 10 years of the FRP's final stage of its operational plan and therefore, it is important to assess its success.

To face these issues caused by fishing activities, controlling of fishing efforts, protection and restoration of fish habitats, and enhancement of fish stocks, are the three prerequisites that can help to recover and sustain the depleting fish stocks (Munro and Bell, 1997; Welcomme and Bartley, 1998; Blaxter, 2000; Bell et al., 2005). The definition of ecological fish stock enhancement covers an enormous diversification of improvement programs including 'marine ranching', 'restocking', 'seaweed forests' and 'artificial reefs' (Bell et al., 2006; Lorenzen, 2008). These programs generate multiple benefits such as increase catch, help rebuilding the stock population and mitigate habitat loss (Howell et al., 1999; Bell et al., 2008).

In recent years, the total production of fish from inshore and offshore fisheries has been depleted from 10 million tons in 1986 to 7.9 million tons until the year 2004 (MOF, 2015). The amount of fish stocks from offshore and inshore fisheries dropped from 10 million tons in 1986 to 7.9 million tons in 2004 (MOF, 2015). To address such fish stocks reduction, ESEPs based FRP have been constantly developed and implemented. The Korean government genuinely acknowledges the necessity to recover depleted fish stocks based on the ESEPs including the artificial reef program, marine ranching program, marine reforestation (seaweed forest) program, production and release of fish seeds program etc.

This paper aims to demonstrate that the ESEPs provides practical management tools and insights in fisheries rebuilding issues and strategies that improve the results of the FRP for sustainable fisheries. Also, this paper intends to show 10 years results of the ESEPs-based FRP both in biological and sociobioeconomic context. The study is based on the procedures and insides of the ESEPs-based FRP as well as details about the management policies of its fisheries. This is also to disclose some present matters for the advancement of the ESEPs-based FRP and to suggest an enhancement strategy to attain the success in ESEPs-based FRP.

\section{The ESEPs-based FRP in Korea}

The ecological stock enhancement programs (ESEPs) : The ecological enhancement of fish stock is a management tool, which is utilized to recover the declined fish stock and an important policy for maintaining and improving fisheries productivity faced with increasing trend of overfished stocks and declining trends of catch in the inshore and offshore fisheries in the Republic of Korea. Nevertheless, the ecological stock enhancement programs (ESEPs) have turn out to be further improved with time, depending on an appropriate arrangement of planning and conducting research to understand and determine the perfect sites, stocking/releasing times, quantity of fingerlings/juveniles, and population genetic structures of the stocks.

The main goal of ESEPs in Korea is to increase fish stock and fishermen's income by improving the restoring productivity for natural population of fish and the marine ecological environment. The ESEPs include many set of programs such as marine ranching, seaweed forest (marine reforestation), construction and installation of artificial reefs, fish seeds production and release to restore and recover fish stocks in coastal and offshore fisheries in Korea. It's very essential to mention here that the FRP together with ecological stock enhancement programs (ESEPs) created a meaningful platform for both government and fishermen to act for improving and recovering the stock condition in coastal and offshore fisheries in Korea (FiRA, 2015).

Regardless of utilizing the traditional management tools of fisheries, for instance, changes/modifications in the types and size-specificities of fishing gears, utilization of short-term closures, and the decline in fishing efforts and harvest of nontargeted species, the production and fish stock have continued to decrease in coastal and offshore fisheries in Korea. A unique method to establish sustainable fisheries is the construction of "productivities" coastal ecosystem, which enhances fish population from key areas, such as breeding, nursing, rearing and sheltering habitats. Under these circumstances, the targeted stocks and the larger fish communities within which they are occupying a part, have given the privilege to recover.

However, some fisheries enhancement programs have occurred for eras and also contributed to a array of ecosystem and community goals, including conserving biodiversity, protecting habitats, helping increase productivity and enhancing fisheries in coastal and offshore fisheries. However, uncertainties still remain about how effective fish stock enhancement programs can be in meeting fisheries rebuilding objectives and recovery strategies, which are summarized in Table 1.

Marine ranching: The marine ranching program has been carried out in 4 main coastal areas of Korea since 1998. This program was conducted by applying manifold networks, based on the University-Institute-Industry Models, to establish the optimum technical and appropriate model development. Marine ranches are created by installing artificial structures such as artificial reefs 
and seaweed forests in the coastal waters providing spawning grounds and habitats for marine life. Releasing large quantities of healthy fish seedlings into the ranch waters and controlling the passages through an effective system to help increase marine resources in the designated area.

With the purpose of inducing continuous enhancement of fish stocks in coastal and offshore fisheries in a short period of time, the technology and experience attained from the marine ranch are applied throughout the entire program. The technology and experience acquired through the marine ranch program will be used to develop marine ranch models that suit each specific sea environment. In order to maximize the effects of the resource enhancement, the program was implemented by a marine ranch utilization management system through mutual cooperation with research institutes and academic/regional organizations, and established in an efficient model for the local government and local organizations, bringing direct impacts to the fish stock rebuilding (NFRDI, 2004; FiRA, 2015).

Marine reforestation (Seaweed forest): The calcification in coastal waters is causing the destruction of spawning grounds and habitats of fisheries, leading to increase in fish stock biomass and productivity of the marine-ecosystem. Marine forest creation programs are in process, with the purpose to restore the fish stock biomass and ecological system, and for this, 47 marine forests have already been created in the period of 2009 to 2015 (FiRA, 2015).

The calcification is causing decrease in potential resources and natural seaweed beds, which have the highest destruction rate of fish stock biomass. This has raised the importance of the sea forest for enhancing the fish stock biomass and the necessity of building a national rebuilding program to restore the fish stock biomass and ocean ecosystem in the territorial waters of Korea (approximately 8 million hectares). Necessities of sea forest to enhance the effectiveness of ocean reforestation by exploring new types of marine plants that can build infrastructure for integrated management of ocean reforestation, through collaboration of the related stock rebuilding program within government departments and concretize the guideline and purpose of sea forest, while enhancing and developing the existing programs (NFRDI, 2004; FiRA, 2015).

Artificial reefs: The artificial reef program was implemented in 1971 to increase fish stocks through the creating habitats and spawning grounds. Between 1971 and 1981, over 1,539 hectares of artificial reefs were deployed. From 1981 until 2001, more than 157,000 hectares of artificial reefs were deployed and through this period, benefits of stock enhancement and increased marine biodiversity associated with artificial reefs have been researched (Muir, 2013). To date, Korea has spent 700 million US dollar on artificial reefs around the country, and for the last decade this has been at the rate of 50 million US dollar annually. According to the report from Ministry of Oceans and Fisheries (NFRDI, 2004), the total area of artificial reefs now installed around Korean waters exceeds 207,000 hectares in 2015 (FiRA, 2015).

Fish seeds production and release: Fish seeds production and release is comprised of artificially producing fish and shellfish by selecting only the young and healthy fish after infectious disease testing, and then releasing them in a suitable environment, with the purpose of increasing marine resources. After releasing the seedlings, continuous investigations and studies of the stocking effects are followed by various methods including monitoring genetic diversity. This includes studying how much seedlings releasing contributes to increasing marine resources and whether a suitable and healthy environment is being maintained after release (NFRDI, 2015-2016).

The current status of fish seed releasing program in which total released amount was 4.85 million seedlings (as of 2011) including Government purchased 1.58 billion seedlings, laboratories 2.5 million seedlings, and local government 770 million seedlings (NFRDI, 2015-2016). Amount of acquired and released seedling was 1.58 million (1986 2012) and $90 \%$ of the

Table 1: ESEPs and its objectives and recovery strategies

\begin{tabular}{|c|c|c|}
\hline \multirow[t]{2}{*}{ ESEPS } & \multicolumn{2}{|c|}{ Ecological stock enhancement strategies and objectives } \\
\hline & Strategies & Main objectives \\
\hline Marine ranching & $\begin{array}{l}\text { - To lead the efforts to rehabilitate } \\
\text { health and abundance. }\end{array}$ & $\begin{array}{l}\text { - Expanding our capabilities for producing healthy young fish. } \\
\text { - Protecting the area of spawning, nursery, feeding, or sheltering habitats. }\end{array}$ \\
\hline Marine reforestation & $\begin{array}{l}\text { - To enhance spawning stock } \\
\text { biomass for the promotion or } \\
\text { acceleration of recovery. }\end{array}$ & $\begin{array}{l}\text { - For effective publicity of the gravity of desolation under the sea and the need of } \\
\text { creating marine forests to recover marine ecosystem in barren ground. }\end{array}$ \\
\hline Artificial reefs & $\begin{array}{l}\text { - Settlement of FRSP-based } \\
\text { Fisheries Management System. }\end{array}$ & $\begin{array}{l}\text { - Contribute to increasing fish stock by providing place for the spawning and growth } \\
\text { of marine organisms. }\end{array}$ \\
\hline $\begin{array}{l}\text { Fish seeds } \\
\text { production release }\end{array}$ & $\begin{array}{l}\text { - Restoration and management } \\
\text { of biological diversity. }\end{array}$ & $\begin{array}{l}\text { - Management of seed resources and releasing by species. } \\
\text { - Restoring productivity for natural population of fish stocks. } \\
\text { - Producing and releasing of young fish. }\end{array}$ \\
\hline
\end{tabular}


Table 3: Sicio-bioeconomic outcomes of 10 years for FSEP-based FRP

\begin{tabular}{lllllllllll}
\hline Year & Sandfish & Blue Crab* & Octopus & $\begin{array}{l}\text { Tokobushi } \\
\text { abalone }\end{array}$ & Skate ray & Cod & $\begin{array}{l}\text { Yellow } \\
\text { croaker }\end{array}$ & File fish & $\begin{array}{l}\text { Korean } \\
\text { flounder }\end{array}$ & $\begin{array}{l}\text { Purplish } \\
\text { W-Clam** }\end{array}$ \\
\hline 2004 & 2,472 & 2,683 & 5,953 & 19 & 259 & 2,641 & 17,570 & 1,267 & 5,345 & 5,380 \\
2005 & 2,401 & 3,714 & 7,637 & 66 & 255 & 4,272 & 15,272 & 1,055 & 5,472 & 6,534 \\
2006 & 2,647 & 6,894 & 7,894 & 54 & 392 & 6,810 & 21,428 & 1,071 & 5,218 & 3,399 \\
2007 & 3,769 & 13,606 & 12,033 & 62 & 375 & 7,533 & 34,221 & 2,998 & 7,326 & 3,422 \\
2008 & 2,720 & 17,596 & 11,838 & 102 & 1,343 & 5,395 & 33,200 & 2,631 & 5,175 & 2,672 \\
2009 & 3,939 & 31,302 & 15,386 & 34 & 3,254 & 6,870 & 34,033 & 8,280 & 5,107 & 1,918 \\
2010 & 4,236 & 33,193 & 10,813 & 27 & 4,131 & 7,289 & 31,931 & 3,475 & 6,671 & 1,950 \\
2011 & 3,834 & 26,608 & 10,421 & 3 & 2,925 & 8,585 & 59,226 & 1,606 & 6,709 & 2,314 \\
2012 & 5,836 & 26,861 & 10,080 & 5 & 2,123 & 8,682 & 36,840 & 1,419 & 6,488 & 2,037 \\
2013 & 6,306 & 30,448 & 9,109 & 5 & 1,651 & 9,133 & 35,280 & 1,295 & 18,171 & 2,199 \\
2014 & 4,678 & 25,310 & 9,881 & 10 & 1,889 & 13,402 & 27,638 & 2,418 & 18,804 & 2,335 \\
2015 & 4,762 & 16,374 & 8,753 & 4 & 2,349 & 7,820 & 33,254 & 2,040 & 17,753 & 1,828 \\
Total recovery & 18,717 & 191,052 & 29,838 & 36 & 16,529 & 14,834 & 132,771 & 5,959 & 32,750 & 0 \\
catch amount(M/T)) & & & & & & & & & \\
Price(2015)(\$MT) & 1,787 & 11,345 & 16,930 & 52,364 & 5,517 & 3,956 & 6,737 & 5,932 & 6,825 & 5,923 \\
Increase revenue & 33.4 & $2,167.5$ & 505.2 & 1.9 & 91.2 & 58.7 & 894.5 & 35.3 & 223.5 & 0 \\
(Million US\$) & & & & & & & & & &
\end{tabular}

*Swimming Crab; **Purplish Washington Clam, Butter Clam; Source: 2016 Korean Fisheries Yearbook, www.fips.or.kr

total quantity obtained from 7 major species including jumbo shrimps, blue crabs, flatfish, Kuruma prawns, Jacopevers, and abalones, while $81 \%$ of the total expense from 7 major species including abalones, flatfish, blue crabs, sea cucumbers, and Jacopevers (FiRA, 2015).

The ESEPs-based FRP : The Fisheries Rebuilding Plan (FRP) is one of the inclusive plan to reestablish fish stock, which is extreme harvest toward a target level in a specific period. Further exactly, the policy goals to enhance the species-wise catch level of fishes from the present to the target level within a rebuilding period, thus it comprises with a sequence of particular and systematic ecological stock enhancement programs (ESEPs) together with the utmost effective fisheries resource management methods as well as complimentary supports from the fishery management bodies.

The FRP has been approved under a national comprehensive approach towards the management of fisheries undoubtedly as a strategy plan under the ESEPs. Initially, it was intended to attain the recovery of fish stock through preventing the existing problems of the traditional management policy. Therefore, it is not the same as the conventional fisheries management policies in various means and ways as follows:

Firstly, because the management of conventional fisheries does not have a clear aim goal of stock rebuilding of overfished fish stocks, the FRP specifies based on the ESEPs is aimed at the recovery of overfished fish stocks in both ecological healthy of stock and catch productivity.
Secondly, the policy for conventional fisheries management was not executed on the basis of systematic investigation and proper assessment on the stock; for ESEPsbased FRP, it stipulates types and contents of a FSEP, which can be utilized upon the analysis of the condition of fisheries and founding a strong stock reestablishing goal with due consideration on the features of the targeted and overfished species under the prevailing ESEPs policy.

The overall objective of the ESEPs based FRP and its management policy is to enhance the depleted and overfished stock of fish to the sustainable level of exploitation. It could be anticipated that this aims to achieve the optimum amount of fish stocks up to the carrying capacity in that specific environment, to break the chains of a vicious cycle of fish stocks exploitation and to maintain a stable catch in sustainable fisheries (MOF, 2015).

Considering the fish stocks condition under specific ESEPs-based FRP, recovery of overfished fish was designated. For target fish, the stock which has been drastically decreased, ESEPs are set up and promoted. As shown in Table 2, the selection of ESEPs for target species of FRP and the recovery of stocks have been estimated by ensuing the stages of realizing biological fish stocks phenomenon in fisheries; investigating appropriate materials and recovery of overfished fish stocks; categorizing fish to recovery of overfished fish species and set the target quantity of recovery. Accordingly, fisheries resource management also enforced the measures of fishing efforts for each fishery and put restrictions on techniques instead of separately managing individual species. Artificial reef programs 
Table 2 : The ESEPs by target species of FRP

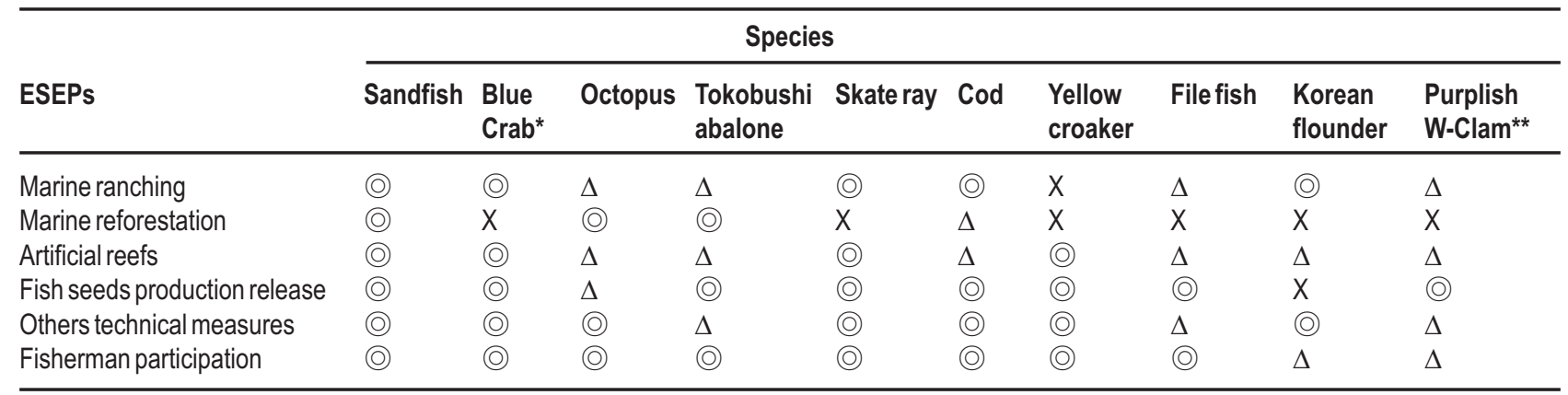

(0) : Completed implementation of ESEPs; $\Delta$ : Semi-ESEPs with other fisheries management measures; $\mathrm{X}$ : No ESEPs; Source: 2016 Korean Fisheries Yearbook, www.fips.or.kr

have been implemented to enhance the overall fish stocks of the coastal areas from the glance-point of ecosystem and the economically important species were managed as well as increased through the fry/fingerling releasing programs.

In addition, interests on the policies and strategies for the management and recovery of individual species have been increased over time since the application of enforcement plan to restore the fishery resources, and such types of efforts are categorized by the prominence on "durability of fisheries" through individual species management in association with ESSPS. Specifically, contrasting to other Nations, recovery of fish stocks is not only promoted through straight limitations on fishing activities. As an alternative, although mainraining fishing operations through the restrictions on individual fishery resources based on ecological systems, it allows the stocks to recover efficiently, rapidly and effectively. Thus, postponement or reduction of fishing activities owing to the recovery of resources could be minimized. At the same time, fishing business can be maintained through relative stability, while promoting resource recovery at the same time (Lee, 2004).

One more characteristic of ESEPs-based FRP is that it postulated the voluntary contribution of fishing community through connection with community-based fisheries management, which in Korea is a recently systematic conventional fisheries management, concentrating on the role of fishing community. Fish community makes voluntary decision to manage and utilize fisheries resources in this system. This community-based fisheries management could be connected with the FRP to actively mirror the views of fishing communities in founding and implementing the plans and to attain dynamic involvement and collaboration in fisheries resources management (Lee and Midani, 2014, 2015). Specifically, it would be beneficial in the way that the effectiveness of the FRP can be maximized through the voluntary acceptance of constraints for the recovery of depleted resources as well as an effective control on unlawful fishing in coastal and offshore fisheries (Lee and Midani, 2015).
Biological and Socio-bioeconomic aspects of the ESEPsbased FRP : To clearly understand the results of ESEPs-based FRP, in this study, we divide these effects into biological and socio-bioeconomic effects. For the biological effects we summarize the integrated results of ESEPs-based FRP on the catch level of targeted species in inshore and offshore fisheries (Table 2). On the other hand, for socio-bioeconomic effects we will show the change in fishing revenues due to change of stock situation and catch levels.

Biological aspects of the ESEPs-based FRP : As stated, ESEPs-based FRP relies largely on catch data from fishers and fishing firms to assess the status of the target fish stocks. The data from 2006 to 2015 for the 8 species among 10 FRP target species shows some earlier catches exceeding targeted limits; however, catches were recently increased and maintained under the limits as ESEPs-based FRP is in its final stage. This recent increase on catches could mean that the increase in self-fishing communities and voluntary participation of fishermen with the ESEPs is having a positive impact on the fish stock and catches. On the contrary, the recent increase in catches below the limits could also mean that fishermen do not provide data that is a true representation of their catch. Thus, the government needs more effective assessment and evaluation mechanism to monitor the implementation of ESEPs-based FRP.

The analyzed catch for 10 species (with exceptions for 2 species), was higher under the 10 years ESEPs-based FRP of the 2004 catch level. These two species are Tokobushi Abalone and Purplish Washington Clam. It is worth nothing that the 2 among the 10-species analyzed were still being below the low catch level in 2015 (Table 3).

The likewise clarification for this inconsistent result is that, for some reasons, FRP target for these stocks are at or much below the present catch levels. The current levels of catch in these two stocks are trusted to be too low regarding to the recent stock size and therefore, are not sustainable, as showed by the fact that there has been overfishing in Purplish Washington Clam under 
ineffective fisheries management and destroyed a harvest and spawning area by coastal development pollution in Tokobushi Abalone in recent years. It is essential to mention here that difficulties related to the recent stock assessment of Tokobushi Abalone are resulting from the indeterminate estimations of MSY (maximum sustainable yield) from this fish stock (Hye et al., 2010).

A "Barren ground (or calcification)" mean that the coastal rocky area is covered with crustose coralline. Barren ground in Korean waters was first reported at Jeju Island in 1992. These events are responsible for the loss of 1,200 ha of marine forests every year. At present, barren ground are over 20,000 ha in the coast of Korea and are one of main causes of destruction of shelter and habitat for many species including Tokobushi Abalone at Jeju Island (Hye et al., 2010).

Careless fry release enhancement programs could diminish the diversity of a species' gene pool, introduce diseases, and alter the structure of species communities. Decisions to use of the stock enhancement for stock recovery should be based on thorough scientific based pilot studies, including analyses of the range of projected economic and social benefits.

Many exploited fish stocks are limited by the supply of juveniles and many also suffer from recruitment overfishing. Consequently, there is much interest in ESEPs, which are aimed at increasing catches by increasing fish stock levels approaching the sustainable fisheries. Most ESEPs involve the release of fryjuveniles reared in hatcheries or the collection, rearing, and transplantation of wild juveniles. Optimized fry-juveniles release strategies and increased fitness for life in the wild are required. The effects of stock enhancement can be measured by marking released juvenile fishes to distinguish them from wild stock, or by large-scale sampling of the target population and of unenhanced control populations.

Several programs for fish stock enhancement of overfished fish species have documented encouraging rates of survival of released fry-juveniles and are reported to be economically viable. In other cases, high production costs for producing stocking sized juveniles, or low survival rates, indicate that fish stock enhancement is not a viable option.

Socio-bioeconomic results of the ESEPs-based FRP : Sociobioeconomically, one major consideration in this analysis is the risk and uncertainty of fisheries management associated with the reducing fishing efforts using fishing closures in FRP. Given the significant uncertainty of fishing effort measures that characterize with fish stock rebuilding plan, there will be uncertainty in achieving expected fish stock trajectories by the reducing fishing efforts such as fishery closures. Fishery closures are the maximizing approach to successful rebuilding, but closures are not likely to be benefit-maximizing nor are they guaranteed to rebuild fisheries in the state of sociall stability (Larkin et al., 2011).
An effective and responsible FRP should be more than simply estimating a long-run target and developing an effective fisheries management on how it is to be achieved. Reducing fishing efforts such as fisheries closures are complex and high economic losses with high business risks so simplistic solutions are likely to be the ESEPs-based FRP.

Without the fisheries closures in FRP, ESEPs-based FRP is one of the effective measures to advocate for the most direct and quickest approach to recover catch levels of overfished fish. This analysis suggests that it is not only socio-bioeconomically worthwhile to stay the course with respect to current efforts of ESEPs to restore overfished stocks, but that much can be gained from strengthening such efforts of ESEPs. As shown in Table 3, the socio-bioeconomic results of 10 years ESEPs-based FRP can be made from analysis. Results are intended to provide insight into socio-bioeconomic outcomes associated with national comprehensive approaches of ESEPs-based FRP.

Until now ESEPs-based FRP for 16 species have been established and are being implemented, including sandfish, swimming crab, octopus, skate ray, cod, yellow croaker, filefish, Korean flounder and purplish Washington clam in 2016. Among them 10 species were selected for 10 years results according to the ESEPs-based ESRP establishment in 2006, 2007 and 2008.

Objective recovery amounts of catch for each step were configured and FRP was simply analyzed by the ecological catch data. Once the amount of catch is subtracted from the objective amount of catch for each year and species, recovery amount during the 10 years period can be calculated. Comparing the catch (of previous year) in 2005, 2006, and 2007, the amount of catch was recovered in most of years during the period of FRP.

Due to the limitations of available data on the ecological stock enhancement from relevant sources, the FRP was simply analyzed. Once the amount of fish catches of previous year is subtracted from the amount of fish catches for the next year under ESEPs-based FRP, the recovery amount of fish catch of each target species during a year can be estimated. Among the catches for 10 species analyzed, the catches of 8 species increased by approximately $10-20 \%$ under the rebuilding plan compared to the initial stage of the 2004-2005 catch level of each species. As shown the 10 years results in Table 3, the total recovery of catch for 10 species is estimated to be 442,486 MT. Once this amount of catch is multiplied by average market price, annual increase in fishing revenue for each target species can be estimated. Considering the 10 years results, total fishing revenue was found to be increased at 4011.2 million USD for 10 species in 2016.

Despite there are efforts of various traditional fisheries management approaches, fish stocks have failed to fully recover to their sustainable levels in coastal and offshore fisheries in Korea. Under the situation of uncertainty of the reducing fishing efforts, the 
ESEPs is an effective fish stock recovery alternative in achieving the objectives of the FRP. The Korean government used ESEPsbased FRP to increase fish stocks and catches by improving the ecological environment and restoring productivity for natural population of fish stocks in coastal and offshore fisheries.

Under specific ESEPs-based FRP, recovering target species were designated considering the fishing catch level, many ecological fish stock enhancements including marine ranching, artificial reef, reforestation and fry releasing were actively implemented to increase overall fish stocks and catch of the coastal and offshore fisheries. From the viewpoint of overall coastal ecosystem, the targeted species of fishes were particularly managed and enhanced through the prescribed policies of ESEPs.

It is not possible to build and promote the ESEPs-based FRP for the recovery of all overfished targeted fish species under the present policy with inadequate scientific research and evaluation systems of resources as well as shortage of fish stock assessment/management institutions in the local and central governments. With the exception for a few species, in major instances, evidence available to assess the situation of specieswise fish stock is mainly based on yearly catch data. It has been observed that many of the targeted species were recovered upon the proper implementation of ESEPs and hence, fishermen's income has increased due to the higher catch.

One of the interesting socio-bioeconomic aspects of ESEPs-based FRP is the encouragement of community-based fisheries management. In order to have better reflection of the ideas of fishermen and to have effective involvement and cooperation of fishing communities in executing the ESEPsbased FRP, the community-based fishery was introduced and implemented in Korea. All the way through the active participation and utmost regulation of illegal fishing by fishermen, the efficacy of the ESEPs-based FRP could be maximized.

The ESEPs for recovery of target overfished species increased over time since fisheries management plans has been implemented to recover fish stocks, and the ESEPs-based FRP is characterized by the prominence on "durability of fisheries" through the effective management of fish species in association with ESEPs. That is, unlike of other nations, recovery of depleted fish stocks in not only protected through direct restrictions That is, unlike of other nations, recovery of fish stocks is not only promoted through direct restrictions. Instead, while maintaining and controlling destructive fishing activities through restrictions on selected fish stocks, the ESEP-based FRP permits efficiently and quick recovery of fish stocks by the direct impacts of ESEPs. Thus, postponement or reduction of fishing activities due to recovery of fish stocks could be minimized under the prevailing ESEPs policies and strategies. Consequently, fisheries business can be maintained with comparative stability while promoting recovery and the same time under ESEPs policies.

\section{Acknowledgment}

We acknowledge that this work was supported by a Research Grant from Pukyong National University, Korea.

\section{References}

Bell, J.D., P.C. Rothlisberg, J.L. Munro, N.R. Loneragan, W.J. Nash, R.D. Ward and N.L. Andrew: Restocking and stock enhancement of marine invertebrate fisheries. Adv. Mar. Biol., 49, 1-370 (2005).

Bell, J.D., D.M. Bartley, K. Lorenzen and N.R. Loneragan: Restocking and stock enhancement of coastal fisheries: Potential, problems and progress. Fish. Res., 80, 1-8 (2006).

Bell, J.D., K.M. Leber, H.L. Blankenship, N.R. Loneragan and A.R. Masuda: Restocking, stock enhancement and sea ranching of coastal fisheries resources. Rev. Fish. Sci., 16, 1-9 (2008).

Blaxter, J.H.S.: The enhancement of marine fish stocks. Adv. Mar. Biol., $38,1-54(2000)$.

Fisheries Resources Agency (FiRA): Annual Report on Stock Enhancement Programs. Busan, South Korea (2015).

Howell, B.R., E. Moksness and T. Svasand: Stock enhancement and sea ranching. Oxford: Fishing News Books, Blackwell Science Ltd (1999).

Hye, S.A., H.S. Wan, E.M. Kim, J.H. Lee, J.K. Noh, H.C. Kim, C.J. Park and B.H. Min: Comparative genetic diversity of wild and released populations of Pacific abalone Haliotis discus discus in Jeju, Korea, based on cross-species microsatellite markets including two novel loci, Anim. Cells Syst., 14, 305-313 (2010).

Larkin, S.L., S. Alvarez, G. Sylvia and M. Harte: Practical Considerations Using Bioeconomic Modeling for Rebuilding, OECD Food, Agriculture and Fisheries Papers No. 38, OECD Publishing, Paris (2011).

Lee, S.G.: A Vision of Korean Fisheries and Policy Directions. Ministry of Ocean and Fisheries (MOF), Sejong, South Korea (2004).

Lee, S.G. and A.R. Midani: National comprehensive approaches for rebuilding fisheries in South Korea. Marine Policy, 45, 156-62 (2014).

Lee, S.G. and A.R. Midani: Fishery self-governance in fishing communities of South Korea. Marine Policy, 53, 27-32 (2015).

Lorenzen, K.: Understanding and managing enhancement fisheries systems. Rev. Fish. Sci., 16, 10-23 (2008).

Ministry of Ocean and Fisheries (MOF). Plans for Mid and Long-term Development of Fisheries Management, Sejong, South Korea (2015).

Muir, J.: Fish, feeds and food security. Anim. Front., 3, 28-34 (2013).

Munro, J.L. and J.D. Bell: Enhancement of marine fisheries resources. Rev. Fish. Sci. 5, 185-222 (1997).

National Fisheries Research and Development Institute (NFRDI). A Symposium on the Fish Stock Rebuilding Plan. Sejong, South Korea (2004).

National Fisheries Research \& Development Institute (NFRDI). Annual Workshop on Fish Stock Rebuilding Plan. Busan, South Korea, (2015-2016).

Welcomme, R.L. and D.M. Bartley: Current approaches to the enhancement of fisheries. Fish. Manage. Ecol., 5, 351-382 (1998). 